\section{Cultural distance and identities-in- construction within the multicultural mathematics classroom}

\author{
Núria Gorgorió, Barcelona (Spain) \\ Núria Planas, Barcelona (Spain)
}

\begin{abstract}
In this paper we present and exemplify our interpretation of some theoretical constructs that have proved useful to our understanding of the complexity of multicultural mathematics classrooms. Constructs such as culture, cultural distance, cultural conflict and identities-in-construction have oriented our study of the complexity of highly multicultural mathematics classrooms in Barcelona. The purpose of this paper is to discuss how cultural distance arising from the different meanings that students, being local or immigrant, inevitably bring to the mathematics classroom may turn into cultural conflicts when cultural interaction is not facilitated through classroom discourse. The lack of cultural interaction and communication may give rise to strong negative feelings and refusal to participate on the side of the students. Students' nonparticipation can be understood as an active response to cultural distance and negative opinions in order to safeguard the identities they (wish to) construct within a context that they perceive as hostile.
\end{abstract}

\section{About the project}

The increasing number of migrant people, refugees, and displaced persons, and therefore, of youngsters living in places with languages and cultures different from that of their families, is a result of the world globalisation process. The Spanish educational system must face the needs of a society where the plurality of cultures and languages is, and will be, a reality. The social fabric that we will have in the near future depends, to a great extent, on the way schools serve, meaning giving service and being useful to, those that at present are considered as not belonging to mainstream social groups and culture.

In Catalonia, an autonomous region within Spain where our research is taking place, immigrant children attend public schools that are abandoned by children belonging to local families who can afford to send them to a private school. Therefore, in some schools, the percentage of immigrant students is rising very fast. Such students face a school system that has a limited understanding of the linguistic and socio-cultural aspects linked to teaching mathematics in multicultural situations. Moreover, there is a widespread social perception that the 'global level of attainment' in public schools is dropping dramatically because of the inclusion of immigrant students. While some local educational administrations and schools are introducing inclusive policies, and some teachers are finding ways that seem to be successful, the rules and laws that develop the Ley Orgánica de la Calidad de la Educación, LOCE 10/2002 (Spanish Educational Act) tend to promote segregation. In general, teachers are not prepared for teaching in multicultural classrooms; the curriculum is intended for the 'native' groups and language, understood as everyday language, is the only 'problem to be solved'.
The beginning of our project was the result of a request from the Catalan Ministry of Education. The aims of the project were a result of an initial negotiation and they included, among others:

a) to know more about the knowledge that immigrant students bring with them to school and how this knowledge can be linked with the curriculum and its development in class;

b) to uncover the values and expectations immigrant students associate with school mathematics and out-ofschool mathematics and how these values and expectations could help or interfere with the teaching and learning of mathematics, and;

c) to develop both proposals and practical examples of how to adapt the school curriculum and classroom organisation to the multicultural classroom.

Working collaboratively with teachers, we developed examples of local curriculum adaptations, teaching materials and classroom activities, ways of structuring time and space, possible classroom organisations and student groupings that proved to be inclusive (see Gorgorió; Planas; Vilella 2000; Planas; Gorgorió; Vilella 1999).

The teachers volunteered to join the project, knowing the aims of the study, and being sensitive to inclusion and equity issues. They had agreed to design with us a series of problems to be posed in their classrooms, developed the problem-solving lessons with their students, and had helped us in the process of gaining the parents' permission to observe and video-tape the sessions. There had been an agreement on working collaboratively on problem-solving tasks which, on the one hand would facilitate students' participation and, on the other, would allow us, teachers and researchers, to come to know more about students' values, beliefs and expectations.

An extensive micro-ethnographic case study was also developed for three months in three classrooms. The choice of an ethnographic methodology was mainly based on the assumption that, in order to understand the meanings attached to classroom episodes by different individuals, one must attempt to interpret the context from their perspectives. The sessions on problem solving were video-taped and all video-tapes were fully transcribed. The notes taken by the second author, the teachers' field notes and the students' notebooks provided complementary data (for more details, see Planas 2001).

As the project progressed, we soon realised that individuals' participation in the mathematics classroom needed to be considered from a broader perspective. The learning of mathematics of minority students is affected by what takes place within the classroom and in its immediate contexts (Zevenbergen 2000, 2003; Nasir; Cobb 2002).

The challenges that multiculturalism poses in the mathematics classroom are clearly linked to equity issues. One of these challenges is to increase all students' participation, as a first condition for their success as students. Immigrant students' success within the school system is most significant when establishing their future life possibilities, since it is linked to life opportunities and barriers. Ladson-Billings (1997) suggests the need of first 
developing a conceptual interpretation of underlying problems and issues when addressing the subject of equity.

In this paper, we want to share our efforts in search of theoretical concepts to analyse the complexity of the multicultural mathematics classroom. In our understanding, the learning of mathematics has not only to do with individuals' cognitive abilities but also with the students' construction of social and cultural identities. Immigrant students' construction of social and cultural identities within the mathematics classroom while in transition between their home cultures, the school culture and the culture of the society that hosts them has been one of the research focuses of our project. We discuss these issues, introducing the concepts of cultural distance and cultural conflict to do so. We illustrate our discussion with examples from the project.

\section{About culture and cultural distance}

We take, as a starting point, Geertz's (1993) definition of culture: 'it denotes an historically transmitted pattern of meanings embodied in symbols, a system of inherited conceptions expressed in symbolic forms by means of which men communicate, perpetuate, and develop their knowledge about attitudes towards life' (p. 89). We regard the culture of a group as being neither static nor monolithic, but as something in a constant process of creation and recreation.

Indeed, one may also think of the culture of an individual and of their cultural identity. The culture of an individual has not only to do with their ethnicity, language, country of origin or social background, even though these are elements that are commonly understood as constitutive factors of the individual's culture. The culture of an individual has also to do with the many different smaller groups to which the individual belongs. According to Woods (1990):

"pupils both contribute and are influenced by cultures, of which some of the more prominent are social class, gender and race...There are many cultures which might be relevant to particular individuals -cultures based on age, on neighbourhoods, on activities, for example- which might crosscut those above” (p. 141).

Considering identity as the fact of being who or what a person is, and focusing on the characteristics that determine this, we necessarily come to the idea of the individual cultural identity. We understand the student's cultural identity as the traits of their identity that are shaped by the cultures of the groups they are part of. We do not refer to the student's cultural identity as the student having all the traits that could characterise the culture 'at large' of the groups the student belongs to. We do not regard the individual's idiosyncrasy as a direct image of a large culture. The individual's way of acting, thinking or understanding does not necessarily have a direct and unique correspondence with the meanings of their groups' cultures. We are not interested, for instance, in explaining the acts of a Pakistani boy within the mathematics classroom in terms of Pakistani culture and boys' ways of acting within it. Our focus is not on the Pakistani student's 'cultural background' but on how his unique way of understanding what happens within the mathematics classroom can be different from other students' understanding and from legitimated understanding.

The multi-ethnic character of a classroom with immigrant students is something that can easily be seen. Its multicultural character is something that requires a special attention and intention on the side of the observer since it has to do with discordances, more or less evident, in actions and interactions among the participants. If the multicultural character of multi-ethnic classrooms is in some ways expected, in more 'homogeneous' classrooms it is somewhat less visible if not denied. However, we consider any classroom to be a multicultural one, since we understand the student's culture as something polyhedral, having many facets, of which we, teachers and researchers, can only see some.

How do the different, multiple cultures of individuals become apparent when they are to work and live together in the mathematics classroom? Different cultural artifacts, like different algorithms or number symbols, mediate the students' learning processes. However, there are other more subtle ways for different cultures to be present. The different ways of understanding the teaching and learning of mathematics itself and how it has to take place, or the value attributed to having or not having mathematical knowledge, are cultural factors that shape how individuals act and interact within the mathematics classroom.

We understand as cultural distance the distance between how different individuals interpret the same fact, situation, person, event or norm, resulting from living and experiencing them from the perspectives of the different cultures to which they belong. Often mathematics teachers refer to their immigrant students as being 'different' or 'acting or thinking in a different way'. When the term 'different' is used to refer to something taking place within a social context like the mathematics classroom, it means different from what is 'normal'. However, what is 'normal' is defined according to the implicit expectations of the individuals involved in the situation. In this way, teachers consider that their immigrant students are 'different', meaning different from what they would expect a student to be. Immigrant students also find that their teachers behave in a different way from what they would expect.

Samina, a 15-year-old girl from Pakistan, was one of the students in a classroom we were studying. One day, Samina's mother sent us a written note to say that her daughter would miss school for some days and would not come to the mathematics lessons because Samina's cousin had just arrived from Islamabad and she had to talk with her. Samina's teacher was rather puzzled by the note: it was difficult for her to understand that Samina's mother's priorities were based upon a different understanding of the reasons for a girl to attend school. The fact was the same: Samina did not attend school during her cousin's visit. The interpretation was different: it was an interpretation made from the perspective of two different cultures, which attach a very different value to female education. It is important to note that Samina's brother, who was enrolled in the same school, did attend 
his lessons during his cousin's visit.

What is our purpose when introducing the idea of cultural distance? Why distance? We certainly do not use the term distance in a metric sense: there is nothing we want to measure. We want to focus on the idea that there may be a gap in the way different participants interpret, or react to, the same fact or situation, and that this different understanding or reaction cannot simply be ignored. Why cultural? Certainly different understandings and ways of acting could simply be explained in terms of different individual characteristics. However, we refer to these differences as being cultural when the individuals' different cultures endow different meanings and values to the same fact or situation.

Our ongoing study of the immigrant students' transition process has given us plenty of examples of the emergence of cultural distance within the mathematics classroom. The transition process (Abreu; Bishop; Presmeg 2002) of a student moving between two (or more) cultures is a key element in the understanding of the learning of mathematics of immigrant students in mainstream schools. We understand the construct transition not as a moment of change but as the experience of changing, of living the discontinuities between the cultures of the different contexts, and in particular between different school cultures and different mathematics classroom cultures. Transitions include the processes of developing both individual and social identities while coping with new social and cultural (learning) experiences. The immigrant students' learning of mathematics in mainstream schools can be considered as a transition process between cultures, between how the home and the school culture understand, value and use mathematics (Gorgorió; Planas; Vilella 2002).

Throughout our study of immigrant students' transition processes we have identified cases of the emergence of cultural distance. The following are some examples:

\section{a) Cultural distance related to meanings and values associated with mathematical knowledge and to who is mathematically knowledgeable:}

Teacher: I want you to think, for tomorrow, of a mathematical problem or situation that can be linked with this photograph (of a rural market with a female stallholder).

Miguel (a gypsy Catalan student): (the next day) This was a trick! There is no mathematics problem, the woman has never been to school, she does not know mathematics.

(Gorgorió; Planas; Vilella 2002, p. 44)

\section{b) Cultural distance related to the idea of learning mathematics:}

Saima (an Indian girl): Miss, I’m wrong in your class.

Teacher: What do you mean? Why do you say that?

Saima: I do the same mathematics as boys, but I will not do the same work... I do not want to be a mechanic. Please, can I do mathematics for girls?

(Gorgorió; Planas; Vilella 2002, p. 44)

\section{c) Cultural distance related to the expected role of a}

mathematics teacher or the organisation of the mathematics classroom:

Teacher: (insisting to Nadia, a Moroccan girl, and Imran, a Pakistani boy, who refused to work together) I would like you two to work together.

Imran: I do not want, if you insist I do not come back to school.

Nadia: If I have any doubts I ask you, you are the teacher, that is why you are here.

(Gorgorió; Planas; Bishop 2004, p. 116)

Miguel, Saima, Imram and Nadia's cases are some of the examples of cultural distance we observed. We have collected many others that give us evidence of the existence of cultural distance among the different participants in the multicultural mathematics classroom.

Why is it important to consider cultural distance within the mathematics classroom? Once again, our focus goes beyond the simple consideration of the fact that mathematics is a cultural product and that, because of that, we need to take into account the existence of different cultural artifacts, like number, symbols or algorithms. Why then is cultural distance of any interest to mathematics education? The cultural distance in Samina's case does not specifically refer to school mathematics but to school in general. However, there are cultural distances that are clearly linked to the students' perceptions of what is, or should be, the proper way of acting and interacting within the mathematics classroom and to their different expectations regarding their mathematics learning. Thus, Saima's positioning is interpreted in Abreu (2005) as 'being constructed at the intersection of her gender identity, her cultural identity and her identity as mathematical learner' (Abreu 2005, p. 3). In her paper, Abreu discusses how some students develop an acute awareness of the significance of their cultural identity in their school mathematical learning and how it may interfere with their actual learning processes.

Although the examples that we have presented here refer to students from minority backgrounds, this is not by itself the cause that leads us to talk about cultural differences and cultural distance. Our research has also shown that cultural distance exists both in schools with immigrant students, whether they are a majority or not, and in schools with no immigrant students at all where cultural distance has also been documented among white middle-class students (see, for instance, Gorgorió; Planas; Bishop 2004).

\section{About cultural conflict}

Cultural conflicts (Bishop 1994, 1998, 2002) and disruptions between the various meanings that different persons attach to the same situation are, perhaps, the most visible manifestations of cultural distance in transition processes lived by the participants in a multicultural classroom. Cultural distance is at the basis of cultural conflicts within the mathematics classroom because of the cultural nature of the learning situation, its norms, its values, the types of its discourse, the communication patterns, etc. Individuals may have differential responses to their experiencing of cultural conflicts, responses that may vary from behaving disruptively to silently breaking 
down their participation.

Cultural conflict is a construct referring to affective aspects of a particular situation, which are assumed to involve antagonists in some sense (Moscovici 1976). When a student experiences cultural distance and the interaction around them, instead of leading to negotiation of meanings, carries with it hostility, confrontation or non-communication, then cultural conflict is ready to appear. Its possible consequences are rejection or acquiescence (Bishop 1998). However, Bishop’s (1994) interpretation of cultural conflicts as being unavoidable, avoidable or minimizable suggests the need to explore how negotiation of meanings and cultural interaction (Bishop 2002) may help to reduce conflicts.

In the next paragraphs, the case of Ramia ${ }^{1}$ will allow us to illustrate how initial cultural distance, that could have been reduced, turned first into acquiescence and then into rejection. Before coming to Spain, Ramia, a 15-year-old Moroccan girl, had attended a French private school near Casablanca. She and her mother left their country due to the social difficulties they were facing after her mother divorced. Ramia arrived in Barcelona carrying all her mathematics textbooks, but few clothes. After her arrival, they could no longer afford a middle class life-style. Ramia frequently talked about her former school and had established little affective relationship with her current classmates.

Ramia's mathematics teacher was participating in the on-going in-service workshop, led by the authors, as part of the project on multicultural mathematics classrooms. Her class were working on problem-solving, first discussing the problems in small groups. Afterwards, a general discussion was led by the teacher. In the particular session we are referring to, the problem that the students were working on described an apple cake recipe with the ingredients for three people. The students were required to find out the necessary quantities for ten people. Ramia was discussing the problem with her peers in a small group, in particular with Lidia.

The initial divergence arising between Ramia and the other participants was linked to a difference in the understanding of the role of the contextualisation of a problem when solving it. The teacher introduced the importance of taking into account the real context suggested. However, Ramia approached the problem on the basis of routine mathematics. The following excerpt is part of the group discussion:

Lidia: Ramia, I think you have made an error; you cannot take 6.666 eggs.

Ramia: (ignoring Lidia) Teacher, how many decimal places do we need to take?

Teacher: Are you sure of taking decimal numbers?

Ramia: Completely sure. I obtained 6.666 by multiplying 2 eggs by 3.333, and 3.333 comes from dividing 10 by 3 .

Lidia: You have to divide it only approximately.

Ramia: This comes from a recipe book! It must be exact. We cannot change it!

Lidia: Stop worrying about the recipe book! Don't be so fussy!

Teacher: OK, Ramia, don't confuse the issue, proportional reasoning must be applied according to each particular context. Your mathematics should be more flexible.

Ramia: (aggressive) OK. You are the teacher. Do I have to write it all over again?

Our analysis here is mainly related to the excerpts that we present, though some comments are also based on data from other excerpts of the classroom transcripts. We understand the lack of agreement in the excerpt above not as a cultural distance related to Ramia being an immigrant, but as a cultural distance related to Ramia and Lidia having participated in classroom cultures where mathematics was understood as having to do with algorithms or with real life solutions. Ramia used accurate quantities instead of introducing the real context into the discussion. However, Lidia, a local lowachieving student, did not feel the need for exact quantities since she knew that, at the end, the answer had to have meaning in its context. Lidia tried to persuade Ramia, with little effect. The teacher soon introduced the legitimate procedure. However, neither Lidia, nor the teacher explained the reasons for it.

Ramia did not understand why her answer was not accepted, but eventually she seemed willing to accept the 'expert' opinion coming from the teacher, without questioning the legitimate interpretation. She seemed to be acquiescing to the legitimate meaning. During the next five minutes many important negative opinions towards Ramia and her contributions were made explicit. She did not receive enough support either to maintain her interpretation, or to question the reasons for it. Lidia and the teacher saw no need to discuss Ramia's contribution.

The following excerpt is part of the conversation developing before Ramia abandoned participation:

Lidia: We need to take six or seven eggs, rather seven than six.

Teacher: Why do you prefer seven?

Lidia: Ramia multiplied and got 6.666 which is nearer seven than six.

Teacher: Do you agree with that, Ramia?

Lidia: She doesn't agree with that! She made an error...

Ramia: (silent and stubborn)

Ramia did not answer the teacher's question. The teacher paused, and then repeated the same question. Ramia remained silent making no other comments during the rest of the session. She only wrote down in her notebook her own results, over and over again, while looking angrily at Lidia and the teacher. Ramia found it difficult to hold on to her position since her contributions or she herself were not being favourably considered. Her position was weakened and she gave up (or she seemed to give up) her own meanings, adhering to legitimated points of view, in an effort to be accepted as part of the group. Nevertheless, her comments were not acknowledged as valuable.

The possibility of co-constructing meanings that would enable the students to understand that mathematical practices are sociocultural in their nature and that there is more than one way to approach them, was not available. There was no cultural interaction (Bishop 2002) 
facilitated by the teacher. After Lidia said, 'She made an error...', there was no attempt to help Ramia to make explicit her reasons for her solution. They all missed a key opportunity to reflect upon circumstances when 'mathematical rigour' may be counterproductive to real life solutions. Lidia, despite having said that Ramia made an error, worked out her approximation drawing on Ramia's solution. However, she appropriated the solution without acknowledging Ramia's contribution as valuable.

Ramia, facing a cultural gap, initially showed acquiescence with the legitimate meaning, in an effort to be accepted as part of the group, as we came to know from interviewing her. Later on, however, seeing that the meanings she was suggesting were rejected, she gave up participating. The reason for Ramia abandoning participation could be the discrepancy in the mathematical meanings assigned to 'contextualise and decontextualise when solving a problem'. However, we are more inclined to believe that Ramia's breaking down her participation had more to do with the interaction process that took place, an interaction process that instead of being a 'cultural interaction process' was an 'obstructed negotiation process' where the contributions of some participants were imposed or acknowledged, while others were ignored or rejected, where some students were accepted, while others were valued negatively.

We have presented an example where the initial cultural distance was not necessarily connected with the fact that the student experiencing it belonged to a minority group. However, the obstructed negotiation of meanings that followed this initial cultural distance had certainly more to do with the student being an immigrant. Although Ramia was mathematically talented, her meanings were not seriously taken into account in this episode. Immigrant students, most of them socially at risk, tend to be stereotyped as less competent and their mathematical abilities have traditionally been considered from a deficit model approach. Therefore, in-transition students and their practices are more prone to be valued negatively due to a priori socially constructed assumptions. This valuing interferes with the orchestration of negotiation of meanings (see Gorgorió; Planas 2005, for a full argument).

\section{About cultural conflicts and identities-in-transition}

In the previous section, we have shown how Ramia, experiencing cultural distance and having her ideas rejected, found it difficult to maintain her engagement. However, in our study we have also documented that many other students maintain their participation despite experiencing cultural distance and having been valued negatively. The question is then: 'What are the reasons for a different reaction to a priori similar factors influencing the students' transition processes?'

Whether conflict or agreement results from interaction dealing with cultural distance will ultimately depend on the student: it is the student's response and construction of the whole interaction that conditions what happens. The issues then are:

- What are the continuities and discontinuities, between the meanings and values attached to the different moments of mathematics learning process by the different participants?

- Why do some students resist adopting legitimated meanings within the classroom group in which they find themselves?

The cultural distance that inevitably arises in any classroom interaction, together with the articulation of a discourse that does not open participation and communication to everybody, does not facilitate cultural interaction. The absence of negotiation negatively affects some students' participation, leading them to abandon their participation. Cultural distance, when not dealt with so as to be minimised, may turn into cultural conflict. Since cultural conflicts involve strong emotional and affective responses, the students' identity-in-construction may be a clue to understanding why the result of cultural distance may be cultural conflict with its consequent acquiescence or rejection. It is not only meanings that shape action, but the unique re-interpretation of them by individuals. In particular, the individual's reconstruction of meanings is shaped by their in-construction identities and by a process of identification of the individual with a group (Abreu 1999; Abreu; Cline 2003).

Teenagers, and especially those in transition, are in a process of shaping their identities, while living inbetween cultural and social contexts; and in our study, also belonging to socio-culturally deprived environments. All this makes the students in our study especially fragile. To construct their identities, such students have cultural references from their home context and, at the same time, from the context that hosts them. They are part, at the same time, of different social groups.

When constructing their social identities, individuals may (want to) identify themselves with the culture of the group(s) they are (want to be) part of. Identifying oneself with a group not only means wanting to be part of it, but also adhering to the meanings and values of the group. The appropriation of a particular classroom meaning involves a process of identification with the classroom group and its culture. However, being part of a group also requires being accepted by the group. The individuals' social identities have to do, on the one hand, with how they position themselves within the group, and how they see themselves as part of the group. On the other hand, it has to do with how they perceive the others accepting them as members, and positioning them within the group. Individuals re-interpret the classroom meanings depending on the position they hold within the community. However, the position that individuals hold within the classroom is often conditioned by the position they are allowed to hold.

When individuals construct their identities within the classroom it is not only their cultural frames of reference or their cultural backgrounds that play an important role, but also their 'foregrounds'. We understand 'foreground', as in Skovsmose (2005), to mean the opportunities that the social, political and cultural situation provides for a person; however, not the opportunities as they might exist in any 'objective' form, but the opportunities as the person actually perceives them. Students' identities are not only conformed by what they have lived and 
experienced, that has lead them to be the way they are, but also by what they expect to be and what they want to be.

Sajid and Aftab were two Pakistani twin boys in our study. They were 15 years old, and came from a rural area near Karachi. Through the interviews with Sajid and Aftab and the classroom observations, we saw how two students with the same cultural background had different ways of thinking and acting within the mathematics classroom. Sajid worked hard in class, and was 'anxious' to succeed in mathematics. Aftab was always 'happy', wanted to make friends, and was not so worried about learning mathematics. When asked during the interviews about their learning of mathematics and their expectations for the near future, Sajid said he wanted to be a mechanic, while Aftab said: 'I want to be smart'. Through the conversation, we understood that what Aftab wanted was to 'assimilate' himself with those of his friends who, in his opinion, had achieved social success. Even though both Sajid and Aftab had given us evidence of their experiencing cultural distance, we could not interpret this distance only in terms of their cultural background, since in their developing identities, their foreground also seemed to play a significant role.

Cultural distance in the understanding of classroom meanings and negative opinions is neither the determinant nor the only cause for breakdowns in participation. Divergences and negative opinions create situations where in-transition students experience conflicts, particularly between the identities they are developing as participants in different contexts. When those conflicts are not positively resolved because of negative emotions -understood as strong permanent feelings (Evans 2000; Parrott; Harré 1996)- they may prevent the students' participation.

Why should Ramia have kept up with her efforts to work with the others after all the difficulties she encountered, and while feeling rejected? Keeping up her engagement would have required her to accept meanings that were not part of her own system of meanings. It would also have meant that she should have ignored the fact that she was not accepted. The situation required her either to give up her own meanings and values, or to give up being part of the group. Under negative emotions, Ramia choose to abandon her participation.

Our point is that cultural distance starts situations where individuals experience conflicts, conflicts between the identities they are developing as members of different social and cultural groups and conflicts between the different identities they are developing as in-transition students. When these conflicts are not positively resolved by the individual, because of negative emotions and because of obstacles to communication, they may interfere with the student's mathematical learning. The reasons for a different reaction to a priori similar factors have to do with the students being able to give coherence to the cultural distance they experience, and with making them compatible with their beliefs, feelings and emotions: in a word, with the identity they (want to) construct.

The students' non-participation can be understood as an active contest with meanings and negative opinions in order to safeguard their social and cultural identities within a context that they perceive as hostile. Their learning is subordinated to their capacity for making compatible their interpretations of the immediate sociocultural contexts and the identities they (wish to) develop. The difficulties which immigrant students encounter when they have to understand and use 'new' meanings may not lie only in their novelty, but in the fact that meanings are not neutral.

\section{About cultural interaction}

Inevitably mathematical practices have different and dynamic interpretations since individuals have different and dynamic reference systems. It is not always possible for these interpretations to exist together. If the classroom is organised so that participants are not expected to make meanings explicit and there is no room allowed for negotiation, then difficulties in communication may increase. However, if we attempt to create more democratic classroom environments, where mathematics is understood as a socio-cultural project, and teaching is seen as a socio-cultural endeavour, then cultural differences may be dealt with positively and may be transformed into positive learning resources.

Bishop's (1994) interpretation of cultural conflicts as being unavoidable, avoidable or minimisable suggests the need to explore how negotiation of meaning and cultural interaction (Bishop 2002) may help to minimise conflicts. Bishop regards ‘cultural interaction' as a linkage between 'consensus' and 'discordance', being opposite parts of the same process:

"The complementarity between them implies that each contains with it the seeds of the other. Dissonance contains within it aspects of consonance, since in order to disagree one must recognise some common features, and likewise consonance includes the raw material of dissonance. If these conditions are not met there is, by definition, no cultural interaction taking place” (Bishop 2002, p. 198).

Discourse within the mathematics classroom may widen the initial cultural distance and may crystallise it, generating cultural conflict. It may also lead to cultural interaction.

The construct of 'cultural distance' has an intrinsic risk. From a mathematical point of view, the distance between $\mathrm{A}$ and $\mathrm{B}$ is the same as the distance between $\mathrm{B}$ and $\mathrm{A}$. But we may represent to ourselves the distance as the path to be followed to go from $A$ to $B$. Then the path from A to $B$ is no longer the same as the path from $B$ to A, but the opposite one. When A represents the dominant culture, and B represents the culture of the minority student, the construct of 'cultural distance' can easily be distorted by assuming that the distance is the path that minority students, the ones that are 'different', should follow to reach the meanings of the dominant culture, which represents 'normality'. With such an interpretation of cultural distance, cultural interaction becomes impossible.

If we understand conflict as a 'mismatch' between an individual's particular understanding and what is legitimate and established, and distance as the distance from the place where the 'distant individual' stands to the 
place where they have to stand, then conflict resolution can only mean the elimination of difference. This was the case with Ramia; she could either adhere to the legitimate meanings within the classroom, which had been established without her contribution, or reject them by keeping her own meanings. In Ramia's case there was no cultural interaction, nobody moved from their initial meanings with the intention of reaching others.

We should also distinguish between difference and differentiation. Cultural distance has to do with differences in understanding particular situations, facts, strategies or content. Differentiation has to do with maintaining (intentionally or not) or increasing the initial cultural distance, and therefore it has to do with cultural conflict. Resolution of cultural conflict should not be the elimination of cultural differences, but explicit engagement in cultural interaction, with its consensus and dissonance. Resolution of cultural conflict should not be about differentiating between those who exhibit differences.

There is much research needed on the conditions required for explicit cultural interaction to take place. The extent to which taking into account cultural identities and cultural distance can help a change from culture-free to culturally sensitive practices in the mathematics classroom is also a question for further research. Researchers should reflect on issues such as:

- What is the culture with which the students are coming into conflict?

- Through which processes can acquiescence be gained or rejection generated?

What the learners conflict with in the mathematics classroom may not only be the mathematical meaning of a particular piece of content or a particular strategy, but the whole act of being taught through processes that ignore, reject or make invisible some students, processes destined to select a few and fail the rest.

There should be room in the mathematics classroom, and in the curriculum, to present mathematics as a practice that is neither a privilege nor a property of the dominant groups. To develop approaches to mathematics education that are sensitive to the learners' cultural identities, will benefit not only minority students but all students. There should be room in classroom discourse for negotiation of meanings and cultural interaction in order to build up, as a joint construction, the classroom culture. In this way, the classroom culture, which is one of the factors that contribute to shaping individuals' polyhedral identities, could include all and every individual, minimising or avoiding cultural distance through negotiation of conflict. We would agree with Moscovici (1976) in arguing that:

"we will only be able to speak of genuine social change when we (...) make the group as a whole, its norms and its attitudes the target of change, and make individuals and minorities the source of these changes" (p. 98).

\section{Final remarks}

Cultural distance may turn into cultural conflict and, when the student feels this conflict to be insurmountable, may prevent the student's participation in mathematical practice, and therefore learning. Therefore, students' participation depends not only on their mathematical competence. The mathematics classroom being a social context, the different opportunities for communication and participation are not merely based on differences in mathematical abilities, but on how the different participants and the knowledge they exhibit are valued by others.

Immigrant students' practices do not conform to the established 'normality', and their mathematical competence tends to be denied. The ability to perform well in a particular mathematical task is not sufficient to succeed in practice. 'To do well at mathematics' is also culturally determined. Immigrant students need to conform to legitimated meanings which, being most of the time implicit, are at the basis of cultural distance and often at the origin of cultural conflict. Hence, cultural distance contributes in hiding the mathematical competence of some students and has to do with their failure as mathematics learners.

However, it is not enough to interpret failure in terms of cultural distance experienced within the mathematics classroom. We should also take into account the larger social context. The larger context helps us to understand what counts as valid mathematics and who counts as a valid doer of mathematics. To better interpret differences in learning opportunities, we need to integrate in our analyses the micro and macro social context, together with the individual (Abreu 2000). Ramia's experiences within the classroom cannot be dissociated from her experiences outside the school, experiences related to her social class and her socio-economic situation.

In particular, the larger social context influences the understanding of negotiation within the mathematics classroom. What is exactly meant by negotiation? Does it mean overcoming obstacles between conflicting ideas? Does it mean compromising in the sense of achieving common meanings that are less than the desirable ones? Is negotiation simply a set of arguments that end up with an act of authority? Or is it something much more complex? In order to answer these questions, it would be helpful to explore to what extent certain valorisations and social representations prevent the so-called negotiation processes.

On the other hand, both teachers and researchers have their own cultural identities and values, which shape their actions and interpretations, leading them to regard certain situations as conflictive. The relevance we attribute to Samina's not coming to school because of her cousin's visit may not be the same as the one attributed by her family or herself. Similarly, the meaning and relevance attributed to negotiation is also culturally constructed. We may regard 'discussing with immigrant students' to be a negotiation. However, do they experience our 'discussing with them' as the negotiation they would expect? Or, more than that, do they expect us to discuss with them at all?

As researchers, we are convinced that negotiation should be one of the elements of the classroom culture. But can negotiation be imposed on teachers and students? Does it make sense that we, researchers, try to establish a meaning for 'negotiation' which is valid in any 
classroom? Negotiation, as the culturally constructed idea that we believe it is, has to have meaning in the particular classrooms where it is applied. Should we not better try to explore the processes that facilitate cultural interaction in order to shorten cultural distance? These processes could allow a shared construction of meaning for the idea of negotiation or, at least, achieve consensus over the need for negotiation.

Notes

1 Ramia's case has been presented elsewhere (Gorgorió; Planas, 2005) to also illustrate how social representations mediate mathematics learning in multicultural mathematics classrooms. That the same case can be interpreted in more than one way illustrates that the complexity of the multicultural mathematics classroom can be, and has to be, analysed from multiple, complementary perspectives. In Gorgorió; Planas (2005) the reader may also find a detailed description of the research method of the study.

2 This paper is part of a research project funded by the Ministerio de Ciencia y Tecnología (BSO2000-01264/psce), the Ministerio de Educación y Cultura (SEJ2004-02462) and the Universitat Autònoma de Barcelona (PRP2004-08).

\section{References}

Abreu, G. (1999): Learning mathematics in and outside school: two views on situated learning. - In: J. Bliss; R. Säljö; P. Light (Eds.), Learning sites: Social and technological resources for learning. Oxford: Elsevier Science, p. 17-31.

Abreu, G. (2000): Relationships between macro and micro socio-cultural contexts: implications for the study of interactions in the mathematics classroom. - In: Educational Studies in Mathematics Vol. 41, p. 1-29.

Abreu, G. (2005): Cultural identities in the multiethnic mathematical classroom. - Paper presented at the Fourth Congress of the European Society for Research in Mathematics Education, Sant Feliu de Guíxols (Spain), February 17-21, 2005.

Abreu, G.; Bishop, A; Presmeg, N. (Eds.) (2002): Mathematics learners in transition - In: G. Abreu; A.J. Bishop; N. Presmeg (Eds.), Transitions between contexts of mathematical practices. Dordrecht: Kluwer, p. 7-22.

Abreu, G.; Cline, T. (2003): Schooled mathematics and cultural knowledge. - In: Pedagogy, Culture and Society Vol. 11, p. 11-30.

Abreu, G.; Elbers, E. (2005): The social mediation of learning in multiethnic schools. - In: European Journal of Psychology of Education Vol. 20(No.1), p. 1-14.

Bishop, A.J. (1994): Cultural conflicts in mathematics education: developing a research agenda. - In: For the Learning of Mathematics Vol. 14(No.2), p. 15-18.

Bishop, A.J. (1998): Cultural conflicts and social change: conceptualising the possibilities and the limitations of mathematics education. - In: P. Gates; T. Cotton (Eds.), Proceedings of the First International Mathematics Education and Society Conference, p. 12-16. Nottingham (UK).

Bishop, A.J. (2002): Mathematics acculturation, cultural conflicts, and transition. - In: G. Abreu; A.J. Bishop; N. Presmeg (Eds.), Transitions between contexts of mathematical practices. Dordrecht: Kluwer, p. 193-212.

Evans, J. (2000): Adults' mathematical thinking and emotions: A study of numerate practices. - London: Routledge Falmer.

Geertz, C. (1973): The interpretation of cultures. - New York: Basic Books.

Gorgorió, N.; Planas, N. (2005): Social representations as mediators of mathematics learning in multiethnic classrooms. - In: European Journal of Psychology of Education Vol. 20(No.1), p. 91-104.
Gorgorió, N.; Planas, N.; Vilella, X. (2000): Cultura y educación matemática: Sugerencias para un cambio. - In: Cuadernos de Pedagogía Vol. 288, p. 72-75.

Gorgorió, N.; Planas, N.; Bishop, A. (2004): Research in a complex social context: Dichotomies, complementarities and tensions. - In: P. Valero; R. Zevenbergen (Eds.), Researching the socio-political dimensions of mathematics education: Issues of power in theory and methodology. Dordrecht: Kluwer, p. 107-123.

Gorgorió, N.; Planas, N.; Vilella, X. (2002): Immigrant children learning mathematics in mainstream schools. - In: G. Abreu; A.J. Bishop; N. Presmeg (Eds.), Transitions between contexts of mathematical practices. Dordrecht: Kluwer, p. 23-52.

Ladson-Billings, G. (1997): It doesn’t add up: African-American students' mathematics achievement. - In: Journal for Reseach in Mathematics Education Vol. 28, p. 697-708.

Moscovici, S. (1976): Social influence and social change. London: Academic Press.

Nasir, N.S.; Cobb, P. (2002): Introduction to the Special Issue 'Diversity, Equity and Mathematical Learning'. - In: Mathematical Thinking and Learning Vol. 4(No.2-3), p. 91102.

Parrott, W.; Harré, R. (1996): Some complexities in the study of emotions: Social, cultural and biological dimensions. London: Sage.

Planas, N. (2001): Obstacles en l'aprenentatge matemàtic: La diversitat d'interpretacions de la norma. - Bellaterra: Publicacions de la Universitat Autònoma de Barcelona.

Planas, N.; Gorgorió, N. (2004): Are different students expected to learn norms differently in the mathematics classroom? In: Mathematics Education Research Journal Vol. 16(No.1), p. $19-40$.

Planas, N.; Gorgorió, N.; Vilella, X. (1999): Fiayaz en el aula de matemáticas: Un ambiente de resolución de problemas. - In: SUMA Vol. 30, p. 65-75.

Skovsmose, O. (2005): Foregrounds and politics of learning obstacles. - In: For the Learning of Mathematics 25 (1) 4-10.

Woods, P. (1990): The happiest days: How pupils cope with schools. - London: Routledge Falmer.

Zevenbergen, R. (2000): “Cracking the code” of mathematics classrooms: School success as a function of linguistic, social and cultural background. - In: J. Boaler (Ed.), Multiple perspectives on mathematics teaching and learning. Westport: Ablex, p. 201-224.

Zevenbergen, R. (2003): Ability grouping in mathematics classrooms: a Bourdieuian analysis. - In: For the Learning of Mathematics Vol. 23(No.3), p. 5-10.

\section{Authors}

Gorgorió, Núria, Associate Professor, Departament de Didàctica de la Matemàtica, Universitat Autònoma de Barcelona, G5142, Bellaterra, 08193, Barcelona, Spain. E-mail: Nuria.Gorgorio@uab.es

Planas, Núria, Dr., Departament de Didàctica de la Matemàtica, Universitat Autònoma de Barcelona, G5-140, Bellaterra, 08193, Barcelona, Spain.

E-mail: Nuria.Planas@uab.es 